\section{Assistência em contracepção e planejamento reprodutivo na perspectiva de usuárias de três unidades do Sistema Único de Saúde no Estado do Rio de Janeiro, Brasil}

\author{
Contraception and family planning services as \\ viewed by users of three clinics in the Unified \\ National Health System, Rio de Janeiro State, \\ Brazil
}

Maria Luiza Heilborn 1

Ana Paula Portella 2

Elaine Reis Brandão 3

Cristiane da Silva Cabral 1

Grupo CONPRuSUS 4

\footnotetext{
1 Instituto de Medicina Social, Universidade do Estado do Rio de Janeiro, Rio de Janeiro, Brasil. 2 SOS CORPO - Instituto Feminista para a

Democracia, Recife, Brasil. 3 Instituto de Estudos em Saúde Coletiva, Universidade Federal do Rio de Janeiro, Rio de Janeiro, Brasil. 4 Outros membros listados ao final do artigo.

Correspondência M. L. Heilborn Centro Latino-Americano em Sexualidade e Direitos Humanos, Instituto de Medicina Social, Universidade do Estado do Rio de Janeiro.

Rua São Francisco Xavier 524, 6o andar, sala 6015, bloco E, Rio de Janeiro, $R J$ 20550-013, Brasil. heilborn@ims.uerj.br
}

\begin{abstract}
This article presents partial data from a larger qualitative, socio-anthropological survey in five States of Brazil, aimed at grasping the perspectives of users in urban and rural areas on their contraceptive and reproductive experiences, and their perceptions concerning contraceptive and family planning care in the Unified National Health System. The article focuses on findings in the State of Rio de Janeiro from 60 individual semi-structured interviews with users 18 to 49 years of age in two primary care clinics in the State capital and one rural clinic under the Family Health Program (FHP). There was a greater diversity in the use of methods in the capital as compared to the interior, where tubal ligation was the only alternative to the pill. Group education work in the capital expands the possibilities for choice of methods and collective learning, although access to the IUD and tubal ligation is still considered problematic, due to difficulties in providing such care. The health services prioritize care for women that have already begun childbearing, and more care is needed for nonpregnant adult women and adolescents, in addition to strengthening the educational work in the FHP.
\end{abstract}

Contraception; Family Planning; Reproductive Medicine; Reproductive Rights

\section{Introdução}

A atenção à saúde da mulher vem sendo construída no Brasil a partir de sucessivas políticas públicas de saúde. Até a década de 1970, a saúde da mulher era considerada em sua dimensão procriativa, priorizando-se cuidados voltados ao ciclo gravídico-puerperal. A saúde pública tinha caráter pró-natalista e a medicina reforçava a naturalização das diferenças entre os sexos, enfatizando a visão da mulher como mãe 1,2. A difusão dos métodos contraceptivos modernos (pílula) e o debate sobre regulação da fecundidade foram impulsionados por políticas internacionais de controle populacional. A não priorização da saúde reprodutiva na agenda nacional deixava espaço para atuação de agências internacionais, principalmente entre camadas populares. Os contraceptivos orais espalham-se pelo país, incentivados pelos médicos e pela propaganda do setor farmacêutico 3 , sem diretrizes estruturadas de planejamento familiar para os serviços de saúde. A transição demográfica, no Brasil, foi efetivada sem uma política oficial explícita que pudesse ser apontada como responsável pela significativa queda da fecundidade nas últimas décadas 4 . Assim, não houve uma drástica transformação das mentalidades e dos comportamentos sexuais e reprodutivos entre homens e mulheres 5,6 e persistem ainda muitos desafios no campo da assistência à contracepção. 
No início da década de 1980, com o processo de redemocratização da sociedade brasileira, os movimentos sociais passam a contestar o regime político vigente e a reivindicar a reformulação do modelo de assistência à saúde no país. Amplos debates ocorreram envolvendo sanitaristas, profissionais de saúde, pesquisadores, sindicalistas, feministas, que lutavam pela reforma da saúde brasileira, pautada nos princípios da universalidade, equidade e integralidade 1,2,7.

No âmbito da saúde da mulher, o movimento feminista participou diretamente da formulação do Programa de Assistência Integral à Saúde da Mulher (PAISM), lançado em 1983, pelo Ministério da Saúde. O PAISM representou um marco na história das políticas públicas voltadas às mulheres, incorporando seus direitos de cidadania. Seus princípios questionavam a relação autoritária entre profissionais de saúde e usuárias, enfatizavam as práticas educativas e criticavam as políticas demográficas 1,2,7,8. Quanto à contracepção, o PAISM acatava a separação entre sexualidade e procriação, defendia o respeito à autonomia dos indivíduos envolvidos no processo reprodutivo, condicionando a oferta de métodos à intenção da mulher ou do casal em limitar a prole.

No Município do Rio de Janeiro, até início dos anos 1990, o PAISM restringia-se a algumas ações de assistência clínico-ginecológica na rede básica, além do pré-natal 9,10. Em 1991, o diagnóstico das ações oferecidas revelou cobertura insatisfatória, qualidade questionável do atendimento, precárias condições de trabalho, baixos salários e dificuldades gerenciais 10 . A equipe gestora decidiu então promover mudanças nas ações de contracepção. O trabalho educativo em grupo foi privilegiado, discutindo a fisiologia do aparelho reprodutor masculino e feminino, sexualidade, métodos anticoncepcionais, com metodologias que incentivam a participação das usuárias. Embora existam diferenças entre as unidades de saúde do município, há sempre a inscrição nos grupos educativos, participação nas reuniões (de 2 a 5), consulta clínico-ginecológica (após o grupo). Ao final, opta-se dentre os métodos contraceptivos disponíveis, com agendamento para acompanhamento clínico-ginecológico ${ }^{11}$.

Na gerência do PAISM no Município do Rio de Janeiro estiveram profissionais de saúde comprometidos com a defesa dos direitos das mulheres na relação com os serviços públicos de saúde. A permanência da mesma equipe, por mais de uma década, na gestão do programa, assegurou continuidade e cumprimento de objetivos estratégicos traçados.

O artigo retrata resultados parciais da pesquisa Contracepção e Planejamento Reprodutivo na Percepção de Usuárias do Sistema Único de Saúde solicitada pela Área Técnica de Saúde da Mulher, do Ministério da Saúde, com apoio do Fundo de População das Nações Unidas, coordenada pelo SOS Corpo - Instituto Feminista para a Democracia e Departamento Materno-Infantil, da Universidade de Pernambuco. O objetivo da investigação era captar a perspectiva de usuárias de áreas urbanas e rurais sobre suas experiências contraceptivas e reprodutivas, bem como sobre o atendimento em contracepção e planejamento reprodutivo no Sistema Único de Saúde (SUS), em cinco estados do Brasil. Realizada em 2005 e 2006, neste trabalho privilegiam-se resultados do Estado do Rio de Janeiro.

O termo "planejamento reprodutivo" é priorizado ao incorporar mulheres em união conjugal, mas também mulheres com vida sexual sem parcerias estáveis e as que se preparam para iniciar sua vida sexual, considerando-as sujeitos na esfera das políticas de saúde no que concerne à sexualidade e reprodução. Busca-se subsidiar a discussão de políticas públicas voltadas à atenção integral à saúde da mulher, em especial ao evidenciar algumas lacunas no debate entre demandas contraceptivas e reprodutivas das usuárias e o atendimento em planejamento reprodutivo recebido na unidade que freqüentam, no intuito de garantir seus direitos sexuais e reprodutivos 12,13.

\section{Metodologia}

Este estudo multicêntrico de natureza qualitativa, sócio-antropológico, envolveu cinco centros de pesquisa. Os estados participantes são: Amazonas, Pernambuco, Goiás, Rio de Janeiro e Santa Catarina. Os pesquisadores, com formações diversificadas, são oriundos das Ciências Humanas e Sociais, e foram submetidos a um treinamento conjunto. A coleta e análise dos dados ocorreram de forma descentralizada.

Houve contato com as Secretarias de Saúde dos municípios nos quais a pesquisa teria lugar para autorização, identificação e seleção das unidades de saúde. As coordenações estaduais realizaram visitas aos serviços considerando os seguintes critérios: duas unidades na capital do estado - uma com serviço de planejamento reprodutivo bem estruturado, na avaliação dos gestores, e outra com atendimento de planejamento reprodutivo mais precário - e uma terceira em município do interior do estado, que atendesse população rural.

A seleção das informantes nas unidades de saúde da capital foi distinta: na unidade bem estruturada, privilegiaram-se usuárias que haviam 
sido atendidas no planejamento reprodutivo; na unidade menos estruturada, as usuárias foram captadas em diferentes setores, bem como em dias e horários distintos de forma a garantir aleatoriedade no conjunto. As entrevistadas da área rural são usuárias do Programa Saúde da Família (PSF). Por se tratar de um estudo qualitativo, a seleção de informantes não se ateve às questões relativas à representatividade do contexto dos serviços públicos do SUS.

Em cada estado, foram entrevistadas sessenta mulheres com idades entre 18 e 49 anos, nos meses de maio a outubro de 2005 , mediante roteiro semi-estruturado, com 138 questões abertas e fechadas (vinte entrevistas em cada unidade). $\mathrm{O}$ instrumento continha três sessões: caracterização da entrevistada; vida sexual e reprodutiva; atendimento nos serviços de saúde, principalmente no planejamento reprodutivo; tendo sido previamente testado em trinta mulheres, seis de cada estado, sendo duas em cada unidade de saúde escolhida.

Foram raras as recusas em conceder a entrevista e, menos ainda, as desistências de continuála uma vez começada. Os depoimentos foram tomados em lugar reservado nas dependências das unidades de saúde, mantendo-se privacidade e sigilo das informações coletadas. As entrevistas foram gravadas e as respostas às questões abertas digitadas em arquivo próprio. A pesquisa atendeu aos princípios éticos necessários, sendo aprovada pelo Comitê de Ética em Pesquisa da Universidade de Pernambuco, sede da coordenação nacional.

Os resultados retratam alguns aspectos da investigação no Estado do Rio de Janeiro. Neste, as duas unidades selecionadas na capital encontram-se respectivamente na zona sul e norte. Ambas as regiões expressam inúmeras disparidades entre as condições de moradia, saúde, saneamento, segurança e violência. Os serviços são referências para grandes favelas do entorno. A terceira unidade de saúde, vinculada ao PSF, situa-se no interior do estado, a duas horas da capital e atende sobretudo população rural. Esta composição permitiu, por um lado, comparar duas unidades de saúde na capital, prioritariamente voltadas para atenção básica em saúde e, por outro lado, fazer um contraste entre o atendimento de planejamento reprodutivo recebido por usuárias residentes em áreas urbanas e rurais em diferentes unidades do SUS. Elas estão identificadas no artigo como unidade 1 (bem estruturada, cujas informantes foram atendidas no planejamento reprodutivo da unidade), unidade 2 (menos estruturada, sendo as informantes oriundas de diversos setores), ambas da capital, e unidade 3 (interior/rural).
Procedeu-se à análise descritiva simples (freqüência uni e bivariada) das questões fechadas; as perguntas abertas foram tratadas em função dos núcleos temáticos 14 investigados no roteiro: experiência contraceptiva e trajetória reprodutiva e visão das usuárias sobre o atendimento em planejamento reprodutivo nos serviços de saúde. Algumas categorias orientaram a apresentação dos resultados da pesquisa e sua discussão: gravidez (im)prevista; uso de métodos contraceptivos; conhecimento e utilização dos serviços de planejamento reprodutivo; práticas educativas; dificuldades existentes no funcionamento dos serviços; direito de escolha e acesso aos métodos; autonomia sexual e reprodutiva.

\section{Resultados}

\section{Caracterização das informantes} do Rio de Janeiro

A média das idades das usuárias do Estado do Rio de Janeiro é 30,5 anos. Mais da metade das mulheres possui baixo nível de escolaridade (53,3\% têm até o nível fundamental completo). A maioria das residentes no interior possui até o nível fundamental de escolaridade, ao passo que esta é a realidade para $32,5 \%$ das que residem na capital. Metade das mulheres se declarou "branca" (51,7\%) e, o restante, "preta" (18,3\%) ou "parda" (30\%); nenhuma menção foi feita a "amarela" ou “indígena”. Há mais brancas no interior (60\%) do que na capital (47,5\%). Quanto à religião, observa-se uma polarização entre católicas $(41,7 \%)$ e pentecostais (40\%).

Mais da metade do grupo (58,3\%) declarou alguma atividade laborativa, mesmo sem ser remunerada, no mês anterior ao de realização da entrevista. Neste conjunto, somente três mulheres nunca haviam trabalhado (duas na capital, uma no interior). A média de renda familiar per capita foi de $\mathrm{R} \$ 194,70$ (o salário mínimo na época correspondia a $\mathrm{R} \$ 300,00)$.

As famílias são formadas predominantemente por adultos jovens, contendo de 3 a 5 pessoas em $70 \%$ dos casos (média de 3,9 pessoas por domicílio). A maior parte dos arranjos domésticos ( $\mathrm{n}=48$ ) é do tipo nuclear-conjugal; em quatro deles nota-se a convivência do casal, com filhos, e uma pessoa idosa, mãe ou sogra da usuária; foram identificados somente nove casos de famílias monoparentais, com chefia feminina, todos residentes na capital.

As informantes já haviam se iniciado sexualmente, exceto uma moça, no interior, com 21 anos à época da entrevista. As demais tiveram sua primeira experiência sexual entre os 12 e os 
28 anos. Mais da metade das que se iniciaram até os 15 anos de idade não chegaram a concluir o nível fundamental; aproximadamente 1/3 das que se iniciaram aos 19 anos ou depois possuem nível médio completo ou superior.

A maioria das mulheres está envolvida em uma relação afetivo-sexual $(n=50)$ com pessoa do sexo masculino. No momento da entrevista, $70 \%$ se declararam casadas/unidas; no interior, nenhuma se identificou como separada/ divorciada.

\section{Experiência reprodutiva: descompasso entre "o querer" e a contracepção}

Mais de $90 \%$ das usuárias $(n=57)$ tinham experiência reprodutiva, sem distinções entre o contexto urbano ou rural. Deve-se lembrar que o estudo abordou mulheres nos serviços de saúde, sobretudo em unidades de atenção primária, tradicionais contextos dedicados à atenção prénatal, puerperal ou pediátrica.

Estas 57 mulheres relataram um total de 153 gestações, 116 partos e 29 abortos, dos quais 11 foram induzidos. As idades com que engravidaram pela primeira vez variam desde os 13 até os 37 anos. Muitos episódios estão próximos à idade da iniciação sexual: o intervalo entre estes dois eventos é em média 2,3 anos para as mulheres do interior e 3,7 anos para as da capital.

Metade das entrevistadas engravidou antes dos vinte anos completos, sendo duas do interior e duas da capital antes dos 15 anos completos. A média é de 2,7 gestações por mulher. Apenas 18 têm uma gravidez (31\%); outras 26 (45,6\%) declaram 2 ou 3 episódios de gravidez, enquanto outras $13(22,8 \%)$ relatam de 4 até 10 casos. Nem todas as gestações foram levadas a termo. A média de filhos vivos por mulher é de 1,92 (incluindo-se os natimortos, esta média eleva-se para 2,03 ).

Frente a cada gravidez ocorrida na trajetória reprodutiva, a informante deveria responder sobre sua reação inicial: "queria ficar grávida", "não queria ficar grávida naquele momento", "não queria ter filhos", "não queria mais ter filhos", "era indiferente". A pergunta buscava captar em que medida aquelas gestações foram ou não planejadas.

Aproximadamente 1/3 dos casos foram gestações referidas como "desejadas" - "queria ficar grávida" $(36,7 \%)$-; os outros $2 / 3$ encontram-se distribuídos pelas demais alternativas apresentadas. "Não querer ter filhos" ou "ser indiferente" à reprodução estão ausentes dentre as repostas das mulheres rurais, demonstrando o forte imperativo da maternidade neste grupo. Parece ser impensável, em um contexto de reduzidas alternativas de inserção social para mulheres e de maior controle social, como em cidades de pequeno porte ou áreas rurais, excluir a via de constituição de uma família com filhos.

$\mathrm{O}$ fato de a mulher ponderar sobre o desejo daquela gravidez a posteriori pode introduzir um viés, pois para diversas entrevistadas o evento está temporalmente muito distante, o que possibilita reavaliar positivamente tais circunstâncias. Além disso, não querer uma gravidez e explicitar publicamente tal aspecto é particularmente difícil numa sociedade em que a maternidade é culturalmente valorizada como importante atributo da identidade feminina.

As respostas em torno de cada evento levam a cogitar que a maioria dos casos de gravidez foi imprevista/não planejada. Entretanto, o fato de declararem não querer filhos não correspondeu a um comportamento contraceptivo coerente, pois somente $1 / 3$ das mulheres fazia uso de algum método contraceptivo quando engravidaram (em 43 casos de gravidez). Há um descompasso entre a manifestação expressa de não querer uma gravidez e a efetiva tomada de precaução nas relações sexuais.

Dentre as diversas justificativas, chama atenção a recorrente frase "pensava que não podia engravidar", ou ainda o fato de deliberadamente não tomar qualquer medida contraceptiva apesar de manter relações sexuais e não querer ficar grávida. Há os casos em que elas diziam acreditar que não engravidariam porque estavam amamentando, sentindo-se "naturalmente" protegidas; porque consideravam ainda estar sob efeito de métodos hormonais cujo uso fora interrompido algum tempo antes; porque entendiam que o uso contínuo de um método hormonal por alguns anos as protegiam ainda por algum tempo depois de sua retirada, como se impregnasse o organismo para além de seu uso cotidiano; bem como o fato de "não pensar muito no assunto", denotando uma certa displicência com tais cuidados.

Quanto aos métodos por elas utilizados, as informantes relatam, em média, três diferentes tipos de métodos em suas trajetórias contraceptivas. A maioria das usuárias do interior (3/4) usou até dois métodos, enquanto as da capital relatam a experimentação de, no mínimo, dois tipos de método a até oito.

A pílula é o método mais conhecido e utilizado, sobretudo no início. Em seguida, outros métodos são acionados. As mulheres rurais iniciam com a pílula e passam, em metade dos casos, para a laqueadura tubária.

Há momentos de interrupção do uso da pílula, seja porque ela "falhou" e uma gravidez sobreveio, ou em função dos seus efeitos colaterais. Há queixas de enjôos, vômitos, dores de cabe- 
ça, nervosismo. Na unidade 1, a participação no grupo de planejamento reprodutivo sem dúvida concorre para a ampliação do espectro dos métodos aos quais as mulheres podem recorrer. As alterações mais freqüentes aparecem ligadas à adoção da injeção, do diafragma ou ainda da camisinha masculina. A razão mais freqüente para mudança de método refere-se ao esquecimento de tomar a pílula. Contudo, o anticoncepcional oral é também o método ao qual freqüentemente se retorna, justificando-se ser o "mais fácil" de usar ou de se obter, pois o "posto tem". O material das entrevistas aponta para uma fraca interiorização da regularidade da contracepção.

A camisinha não é o primeiro método escolhido ao se iniciar a vida sexual, mas é usado sobretudo no início dos relacionamentos sexuais subseqüentes ao longo da vida, associado à proteção a outras DSTs. Contudo, seu uso é descontinuado assim que o vínculo se firma, quando se passa a ter "confiança" ou "conhecer melhor" o parceiro, fato registrado na literatura 11. O coito interrompido aparece associado ao começo da trajetória sexual e contraceptiva das mulheres, sugerido por colegas ou namorados. Seu fraco potencial contraceptivo é amplamente reconhecido pelas usuárias, embora tal constatação, às vezes, decorra após uma gravidez. As mulheres consideram-no desconfortável na medida em que ele "corta o barato".

O uso do DIU foi declarado por somente cinco informantes. Embora todas sejam oriundas da unidade 1, a colocação do DIU foi obtida em outros locais no caso de duas delas. Entretanto, sempre há longos relatos sobre efeitos colaterais, que implicaram mudança de método para todas. A contracepção de emergência foi mencionada por duas usuárias da capital; ambas mulheres jovens (18 e 23 anos) e com nível médio completo de escolaridade.

\section{Laqueadura tubária: desigualdades e limitações na implementação das políticas de saúde}

Foram encontradas 13 mulheres esterilizadas no momento da entrevista, sendo a maior concentração delas no interior $(n=10)$, em contraste com apenas três da capital. As idades que tais mulheres fizeram a laqueadura tubária são 18 anos $(\mathrm{n}=1), 19$ a 21 anos $(\mathrm{n}=1), 22$ a 25 anos $(\mathrm{n}=33)$, mais de 25 anos $(n=8)$. Nenhuma tinha menos do que dois filhos ao se submeter à esterilização.

Das três usuárias que fizeram a laqueadura na cidade do Rio de Janeiro, duas foram no âmbito do atendimento do SUS, encaminhadas pela unidade 1 para os serviços credenciados. A terceira, que a realizou em 2004, afirmou ter conseguido por apadrinhamento político. Seu relato desnuda freqüentes dificuldades e falhas do serviço de saúde para atender a demanda. Ela participou da palestra de planejamento reprodutivo na unidade 2, aguardava para colocar o DIU, usando então camisinha, mas afirma que houve desencontros entre o único dia da semana que a unidade disponibiliza para inserção do DIU e a ocorrência de sua menstruação. Aos 37 anos, acabou engravidando de novo, tentou abortar o filho, recorrendo ao misoprostol e outros medicamentos; sem êxito, fez a ligadura no parto do terceiro filho. Se a colocação do DIU, logo após sua participação no grupo de planejamento reprodutivo, tivesse sido viabilizada, talvez a terceira gravidez pudesse ter sido evitada.

Dentre as dez mulheres que realizaram a ligadura no interior, sete fizeram-na entre 1980 e 1996, período anterior à implantação da legislação vigente ( $L e i$ $n^{o} .9 .263$ 15) e três entre 2000 e 2002. Elas recorreram a hospitais (públicos e privados) de cidades vizinhas ao pequeno município onde residem, com intermediação de funcionários destes hospitais, conhecidos ou de políticos. Em dois casos, os médicos fizeram a laqueadura sem cobrar, como um "presente" e em outros dois, elas relatam haver pagado pelo procedimento.

\section{Os serviços de planejamento reprodutivo}

A variabilidade dos resultados apresentados decorre da distinta organização e complexidade dos serviços onde as mulheres foram entrevistadas. A oferta e dinâmica de atendimento nas unidades estão caracterizadas pelo prisma de análise das usuárias. A contraposição entre os serviços é feita sempre que pertinente. Ressalta-se que todas as entrevistadas na unidade 1 foram atendidas pelo planejamento reprodutivo daquele serviço, o que não é o caso da maioria das informantes da unidade 2 . As mulheres do meio rural (unidade 3) são usuárias do PSF, o que circunscreve o tipo de atenção recebida.

\section{- Conhecimento e utilização do planejamento reprodutivo nos serviços}

Excluindo-se 14 entrevistadas (13 esterilizadas e uma não sexualmente iniciada), as informantes se dirigem para os serviços públicos de saúde e/ou à farmácia, muitas vezes sem orientação médica, quando querem obter algum método contraceptivo.

A maioria $(n=42)$ sabia que a unidade de saúde na qual se encontravam oferecia métodos de evitar filhos (29 na capital, sendo a totalidade das usuárias da unidade 1 e 13 no interior). Também grande parte respondeu afirmativamente à existência de palestras sobre evitar filhos na unidade (todas as vinte que passaram pelo grupo de planejamento reprodutivo da unidade 1 e dez na unidade 2). As que não sabiam 
informar a esse respeito concentram-se, como era de se esperar, na unidade 2 e no interior (respectivamente, dez e seis mulheres). A maioria das usuárias do PSF foi categórica ao afirmar que este tipo de atividade não existia no posto que freqüenta. Perguntou-se também se conheciam os métodos oferecidos pela unidade, ao que 33 responderam positivamente (19 na unidade 1, seis na unidade 2 e oito no interior), citando: pílula, camisinha masculina, DIU, diafragma e camisinha feminina. No interior, só há menção à pílula e preservativo.

Além das vinte usuárias da unidade 1, outras dez já haviam participado das atividades de planejamento reprodutivo na unidade de saúde na qual foram abordadas (seis na unidade 2 e quatro no interior), assistindo às palestras nos grupos educativos (capital) ou recebendo orientação na consulta com a enfermeira (interior). Algumas mulheres na capital, embora tenham assistido às palestras nos grupos de planejamento reprodutivo, não utilizavam necessariamente o serviço para obter métodos.

Dentre as trinta mulheres que de alguma forma já haviam se beneficiado do planejamento reprodutivo nas respectivas unidades, 23 afirmaram que conseguiram os métodos que queriam (19 na capital e quatro no interior). Dentre estas, os métodos mais utilizados foram: pílula $(n=16)$, camisinha masculina $(n=6), \operatorname{DIU}(n=5)$, laqueadura $(n=2)$, diafragma $(n=1)$ e camisinha feminina $(n=1)$, sendo a oferta dos quatro últimos métodos relatados apenas por usuárias da unidade 1 . Três usuárias da capital que não conseguiram obter os métodos desejados relataram dificuldades para a obtenção da ligadura e o fato de estar em tratamento de infecção para posterior inserção do DIU. Duas outras da unidade 2, como estavam grávidas, no pré-natal, ainda não sabiam se obteriam os métodos desejados. Uma delas aspirava à laqueadura e preparava a documentação pertinente; a outra desejava usar a pílula posteriormente à gravidez.

Excetuando-se as vinte usuárias da unidade 1 (participantes dos grupos educativos), as dez laqueadas e uma virgem, as 29 restantes que não haviam utilizado o planejamento reprodutivo da unidade apontam as seguintes razões: desconhecimento da dinâmica do atendimento; desinteresse ("não procurou saber", "não se interessou”); utilizam outra pílula que a ofertada no serviço de saúde (e temem mudar, pois acham a pílula distribuída pelo posto "fraca", duvidando de seu efeito).

\section{- Atendimento das usuárias por unidade de saúde}

As entrevistadas da unidade 1 responderam assertivamente, tanto no que diz respeito à oferta de métodos quanto à ocorrência de palestras naquele serviço, revelando consonância entre o que é ofertado e a percepção da usuária.

Não é surpresa o fato de que as usuárias do serviço de planejamento reprodutivo da unidade 1 soubessem corretamente sobre oferta de métodos e ocorrência de palestras. Já na unidade 2 , as respostas concernentes à oferta de métodos e às palestras foram bem menos coesas: 11 usuárias não sabiam informar se aquele serviço disponibilizava métodos contraceptivos (oito também não sabiam sobre palestras); metade declarou que sabia da existência de palestras sobre meios de evitar filhos (sendo que seis já haviam participado destes grupos), e a outra metade não sabia informar a respeito (oito não sabiam nada a respeito do planejamento reprodutivo).

No interior, todas afirmaram não haver palestras no posto de saúde que freqüentam e a maioria $(n=13)$ sabia informar sobre a (in)disponibilidade de métodos. Considerandose que as unidades do PSF localizadas na área rural são pequenas, os poucos profissionais que ali trabalham são conhecidos, facilitando o contato com as usuárias.

No tocante à dinâmica do atendimento no planejamento reprodutivo (dias, horários, profissionais responsáveis), as informantes da unidade 1 também sabiam informar sobre dias e horários, referindo-se à disponibilidade da assistente social, responsável pela inscrição no grupo de planejamento reprodutivo e fornecimento do método, bem como sobre os profissionais de saúde que se ocupam destas atividades (assistente social, médico, enfermeira). Na unidade 2, só uma soube informar dia e horário, embora outras entrevistadas tenham mencionado ou citado nominalmente a enfermeira responsável pelo planejamento reprodutivo. No interior, os horários informados pelas entrevistadas confundiam-se com os horários de funcionamento do posto e os dias de trabalho da enfermeira.

As considerações sobre o atendimento do planejamento reprodutivo da unidade 1 sempre são bastante favoráveis, e as usuárias destacam a utilidade das palestras que assistiram. A maioria expressou ter gostado dos grupos de planejamento reprodutivo dos quais participou, ressaltando o fato de ter esclarecido dúvidas e aprendido mais sobre como evitar doenças, gravidez e sobre os métodos. Outro aspecto positivo assinalado é a disponibilidade do método gratuitamente. 
Há distribuição gratuita da camisinha feminina nos grupos educativos da unidade 1 , fato apreciado positivamente, com propósito de ampliar sua divulgação. Embora ela não seja distribuída continuamente no serviço, o conhecimento e a experimentação da camisinha feminina integram a dinâmica do processo educativo, no intuito de incentivar as mulheres a conhecer o próprio corpo e a conversar com os parceiros sobre contracepção.

Na unidade 2, a maioria das usuárias não sabia a respeito do planejamento reprodutivo ali ofertado. Ressalta-se que nem as que estavam fazendo pré-natal ou revisão de pós-parto mencionaram ter passado pelo grupo de planejamento reprodutivo da unidade. Uma chegou a declarar que buscou informação sobre isso, mas não obteve resposta. Algumas usuárias aspiravam à ligadura como método definitivo, preenchiam os requisitos legais para fazê-la e estavam desamparadas quanto às informações de como poderiam viabilizar tal procedimento. Uma informante, de 34 anos de idade, nascida na Paraíba, com dez gestações e quatro filhos vivos, tendo iniciado sua vida reprodutiva antes dos 15 anos, com três episódios de abortos espontâneos, dois deles decorrentes de violência marital (primeiro parceiro), dois natimortos e outro que morreu no dia seguinte ao nascimento, voltava à unidade 2 para revisão pós-parto, sem ter clareza ainda do método que usaria no futuro, após o "resguardo". "Se eu não conseguir a laqueadura, vou usar a injeção", afirma. Ela não havia participado do planejamento reprodutivo na unidade. No decorrer do pré-natal da última filha, mencionou, contudo, ter participado de duas das cinco reuniões do planejamento familiar em outro posto de saúde do município, há dez anos atrás.

No interior, o trabalho de planejamento familiar consiste em uma consulta de enfermagem e distribuição subseqüente do método; não há atividades educativas em grupo. Dentre as que poderiam potencialmente solicitar este tipo de assistência (nove mulheres), somente quatro o fazem. Elas são primeiramente atendidas pela enfermeira e depois continuam a apanhar os métodos com a auxiliar de enfermagem no posto: "Eu fui na consulta com a enfermeira, ela me explicou tudo que tinha aqui, como que usava e passou, não teve palestra e nem demorou".

\section{Discussão}

O modelo de atenção ao planejamento reprodutivo nas unidades básicas de saúde do Município do Rio de Janeiro privilegia as práticas educativas em grupo para que as mulheres possam ter condições de escolher o método contraceptivo que querem utilizar. Tal como outros estudos já realizados, os resultados mostram o quanto estas reuniões de grupo são avaliadas positivamente pelas usuárias, pois se configuram como espaços de troca de experiências e aquisição de novos conhecimentos 9,16. Não por acaso, a diversidade de métodos conhecidos é maior entre as mulheres que freqüentaram o grupo de planejamento reprodutivo do que as demais.

Entretanto, considera-se que as unidades de saúde devam ser sensíveis ao fato de que nem todas as usuárias têm disponibilidade de tempo para tal participação, porque trabalham durante o dia. Condicionar o acesso ao método contraceptivo à participação no grupo educativo tem inúmeras vantagens, mas também pode acarretar importantes perdas no que se refere à captação de contingente expressivo de usuárias interessadas. Talvez a existência de espaços alternativos, individuais, não necessariamente vinculados às consultas ginecológicas, possibilitasse que maior número de mulheres pudesse se informar sobre métodos existentes e fazer suas escolhas.

Salienta-se que o planejamento reprodutivo ainda está organizado segundo a lógica que privilegia a díade materno-infantil. Em ambas as unidades investigadas na capital, o encaminhamento ao planejamento reprodutivo favorece mulheres em atendimento pré-natal e no pós-parto. Não há esforço na mesma magnitude em relação às mulheres que ainda não pariram, não desejem parir ou tenham dificuldades para engravidar. Os serviços de saúde terminam priorizando o atendimento em contracepção a partir do momento em que a mulher já iniciou sua trajetória reprodutiva. Proporcionar às usuárias a possibilidade de iniciar sua trajetória sexual sem risco de gravidez imprevista não integra as prioridades na organização dos serviços. Lógica semelhante está subjacente à atitude das unidades de saúde em relação às adolescentes, que atuam somente quando a moça chega à unidade já grávida, em busca da assistência pré-natal. A sexualidade juvenil, não necessariamente associada à reprodução, precisaria integrar o planejamento reprodutivo no SUS, como aponta investigação recente 17 de modo a prevenir histórias semelhantes às coletadas nesta pesquisa, acerca de abortos clandestinos, sofrimento e adoecimento.

No interior, não há o mesmo envolvimento político da gestão do município na atenção integral à saúde da mulher. Os depoimentos não trazem elementos que evidenciem que as equipes de PSF estejam realizando um trabalho sistemático nessa direção, o que seria fundamental, tendo em vista as expressivas dificuldades encontradas na zona rural em razão de níveis bem 
mais precários de escolaridade. O alto número de usuárias laqueadas, se comparado ao da capital, comprova menor possibilidade de escolha e acesso aos métodos contraceptivos reversíveis.

O processo de consolidação da atenção integral à saúde da mulher tem desafios: o delineamento de estratégias para captar a mulher adulta não grávida, a capacitação de profissionais para abordarem a sexualidade juvenil, o respeito aos direitos sexuais e reprodutivos no âmbito de outros programas de alcance nacional como PSF e Programa de Agentes Comunitários de Saúde (PACS).

Por fim, ressalta-se que o DIU, apesar de ser um método disponível, conhecido e demandado pelas usuárias, é de baixíssima utilização. Quando elas optam por este método, se defrontam com dificuldades e contratempos da organização do atendimento (demora nos resultados de exames, agendamento da consulta para inserção do DIU em um único dia da semana), o que dificulta sobremaneira o acesso. Nestes casos, elas desistem desse método e optam pela pílula ou esterilização. Outra pesquisa feita no Ceará identificou dificuldades semelhantes em relação ao acesso ao DIU 18.

As condições de acesso das usuárias ao planejamento reprodutivo nas unidades de saúde ainda necessitam ser aperfeiçoadas 19. Em cidades de pequeno porte do interior deve-se melhorar a abordagem feita pelo PSF ao tema ${ }^{18}$. Na capital, os problemas se concentram na organização dos serviços, com grande demanda e oferta limitada de grupos em horários diurnos, coincidindo com o horário de trabalho das usuárias, às vezes, com longo tempo de espera para serem atendidas (entre 15 dias a 6 meses). Tais dificuldades, aliadas à interrupção do atendimento (férias dos profissionais responsáveis), irregularidade no fornecimento de métodos, condicionam as possibilidades de escolha das usuárias, às vezes constrangidas a optarem por determinado método (pílula ou camisinha), em razão das dificuldades de acesso a outro, como o DIU ou a ligadura. Estes resultados convergem com os de outra investigação sobre planejamento familiar no Brasil 20, no que tange às dificuldades dos serviços de incluírem o atendimento aos adolescentes, à infertilidade e à contracepção de emergência.

\section{Considerações finais}

Por fim, identificam-se algumas proposições que mereceriam maior atenção dos serviços de saúde: o acesso às laqueaduras tubárias continua a ser problemático, na capital e no interior; a dinamização do atendimento no caso do DIU (agilidade nos resultados de exames, consulta para inserção do DIU, acompanhamento posterior); a captação de mulheres adolescentes ou jovens pelos serviços de saúde, em período anterior à primeira gestação; inclusão da discussão da contracepção de emergência nos serviços de saúde. Salienta-se ainda que as campanhas públicas realizadas pelo Ministério da Saúde em prol da amamentação natural, tão bem sucedidas nos últimos anos, poderiam discutir melhor a associação entre amamentação e proteção à gravidez. Trata-se de um aspecto cultural muito presente entre as usuárias, que relataram diversos episódios de gravidezes imprevistas no período pós-parto, durante a amamentação (não exclusiva), pois se consideravam protegidas por essa prática.

A qualidade do atendimento em planejamento reprodutivo é central para a conquista dos direitos sociais das mulheres, ao favorecer a autonomia sexual e reprodutiva. Embora existam significativas dificuldades para o pleno atendimento das necessidades das usuárias, concernentes ao planejamento reprodutivo (oferta contínua de todos os métodos, melhor captação e encaminhamento de usuárias pelos serviços de saúde, capacitação de profissionais para o trabalho educativo etc.), quando o serviço está bem estruturado, como é o caso da unidade 1, as usuárias que dele participam relatam efeitos positivos - maior segurança, conhecimento e liberdade para vivenciarem a sexualidade sem ocorrência de gestações imprevistas. Sem dúvida, o controle da fecundidade, o espaçamento ou interrupção da vida reprodutiva possibilita às mulheres o exercício dos direitos sexuais e reprodutivos. Entretanto, tal autonomia é permanentemente cerceada por constrangimentos institucionais (horários de atendimento, disponibilidade de métodos, lentidão nos resultados de exames, burocracia etc.), que limitam a cidadania das mulheres usuárias do SUS.

Tais fatos demonstram que há muito que construir na atenção à saúde da mulher, tanto no que se refere à iniciativa política de gestores municipais quanto na perspectiva de melhoria da organização dos serviços e sensibilização de profissionais de saúde para o tema do planejamento reprodutivo como um direito à saúde, no intuito de se alcançar a superação das iniqüidades e a integralidade no atendimento. Conhecer os reais obstáculos para a atenção eficiente em contracepção é nosso maior desafio. 


\section{Resumo}

Este artigo apresenta dados parciais de ampla pesquisa qualitativa, sócio-antropológica, realizada em cinco estados do Brasil, para captar a perspectiva de usuárias de áreas urbanas e rurais sobre suas experiências contraceptivas e reprodutivas, bem como sobre o atendimento em contracepção e planejamento reprodutivo no Sistema Único de Saúde. Enfocam-se resultados do Estado do Rio de Janeiro, mediante sessenta entrevistas individuais semi-estruturadas, com usuárias entre 18 e 49 anos, de duas unidades básicas de saúde da capital e de uma unidade do Programa Saúde da Família (PSF), no interior, em área rural. Constatou-se maior diversidade no uso de métodos na capital, em contraste com o interior, onde apenas a laqueadura se apresenta como alternativa à pílula. O trabalho educativo em grupo na capital amplia as possibilidades de escolha de métodos e aprendizado coletivo, embora o acesso ao DIU e à ligadura ainda seja considerado problemático, devido às dificuldades no atendimento. Os serviços de saúde privilegiam assistência às mulheres em trajetória reprodutiva; há necessidade de atenção às mulheres adultas não grávidas e adolescentes, além do fortalecimento do trabalho educativo no PSF.

Anticoncepção; Planejamento Familiar; Medicina Reprodutiva; Direitos Reprodutivos

\section{Referências}

1. Costa AM, Aquino EL. Saúde da mulher na reforma sanitária brasileira. In: Costa AM, Merchán-Hamann E, Tajer D, organizadores. Saúde, eqüidade e gênero: um desafio para as políticas públicas. Brasília: Editora da Universidade de Brasília; 2000. p. 181-202.

2. Costa AM. Desenvolvimento e implementação do PAISM no Brasil. In: Giffin K, Costa SH, organizadoras. Questões da saúde reprodutiva. Rio de Janeiro: Editora Fiocruz; 1999. p. 319-35.

3. Pedro JM. A experiência com contraceptivos no Brasil: uma questão de geração. Revista Brasileira de História 2003; 23:239-60.

4. Vieira EM. Políticas públicas e contracepção no Brasil. In: Berquó E, organizadora. Sexo e vida: panorama da saúde reprodutiva no Brasil. Campinas: Editora da Unicamp; 2003. p. 151-96.

5. Bozon M. L'évolution des scénarios de la vie reproductive des femmes au Brésil. Médicalisation, genre et inegalités sociales. Tiers Monde 2005; XLVI:359-84.

\section{Colaboradores}

A. P. Portella concebeu o projeto e revisou o artigo. M. L. Heilborn analisou os resultados e redigiu o texto. E. R. Brandão e C. S. Cabral coordenaram a pesquisa de campo, analisaram os resultados e redigiram o artigo. $\mathrm{O}$ Grupo CONPRuSUS foi responsável pela investigação e análise dos resultados regionais.

\section{Agradecimentos}

Colaboraram na pesquisa, no Estado do Rio de Janeiro, J. S. Lima, P. O. Tavares, C. A. Alves.

\section{Outros membros do Grupo CONPRuSUS}

V. Ferreira e B. Ávila (SOS CORPO - Instituto Feminista para a Democracia; Pernambuco), R. M. Albuquerque (Departamento Materno-Infantil, Universidade de Pernambuco; Pernambuco), M. Rovery (Grupo Transas do Corpo; Goiás), L. S. Minella (Núcleo de Identidades de Gênero e Subjetividades, Universidade Federal de Santa Catarina; Santa Catarina), K. L. C. Oliveira e D. M. D. Gutiérrez (Universidade Federal do Amazonas).
6. Minella LS. Gênero e contracepção: uma perspectiva sociológica. Florianópolis: Editora da Universidade Federal de Santa Catarina; 2005.

7. Boaretto MC. Gênero e modelo de gestão em saúde: a experiência do Rio de Janeiro. In: Costa AM, Merchán-Hamann E, Tajer D, organizadores. Saúde, eqüidade e gênero: um desafio para as políticas públicas. Brasília: Editora da Universidade de Brasília; 2000. p. 215-26.

8. Osis MJMD. Paism: um marco na abordagem da saúde reprodutiva no Brasil. Cad Saúde Pública 1998; 14 Suppl 1:S25-32.

9. Pacheco VLG. Avaliação das ações de contracepção na Secretaria Municipal de Saúde do Rio de Janeiro: inovações e obstáculos. Revista Saúde em Foco: Informe Epidemiológico em Saúde Coletiva 2001; 21:137-47.

10. Valladares DP. Ações de contracepção e assistência ao parto: a experiência do Rio de Janeiro. In: Giffin K, Costa SH, organizadoras. Questões da saúde reprodutiva. Rio de Janeiro: Editora Fiocruz; 1999. p. 357-76. 
11. Stephan-Souza AI. Relendo a política de contracepção: o olhar de um profissional sobre o cotidiano das unidades públicas de saúde. Cad Saúde Pública 1995; 11:408-24.

12. Ministério da Saúde. Política Nacional de Atenção Integral à Saúde da Mulher: princípios e diretrizes. Brasília: Ministério da Saúde; 2004.

13. Ministério da Saúde. Direitos sexuais e direitos reprodutivos: uma prioridade do governo. Brasília: Ministério da Saúde; 2005.

14. Blanchet A, Gotman A. L'enquete et ses méthodes: l'entretien. Paris: Ed. Nathan Université; 1992.

15. Senado Federal. Lei no ${ }^{\circ}$ 9.263, de 12 de janeiro de 1996. Brasília: Diário Oficial da União 1996; 15 jan.

16. Osis MJD, Duarte GA, Crespo ER, Espejo X, Pádua KS. Escolha de métodos contraceptivos entre usuárias de um serviço público de saúde. Cad Saúde Pública 2004; 20:1586-94.
17. Knauth D, Heilborn ML, Bozon M, Aquino EML Sexualidade juvenil: aportes para as políticas públicas. In: Heilborn ML, Aquino EML, Bozon M, Knauth D, organizadores. O aprendizado da sexualidade: reprodução e trajetórias sociais de jovens brasileiros. Rio de Janeiro: Editora Fiocruz/Editora Garamond; 2006. p. 399-417.

18. Moura ERF, Silva RM, Galvão MTG. Dinâmica do atendimento em planejamento familiar no Programa Saúde da Família no Brasil. Cad Saúde Pública 2007; 23:961-70.

19. Costa AM, Guilhem D, Silver, LD. Planejamento familiar: a autonomia das mulheres sob questão. Rev Bras Saúde Matern Infant 2006; 6:75-84.

20. Osis MJD, Faúndes A, Makuch MY, Mello MB, Sousa MH, Araújo MJO. Atenção ao planejamento familiar no Brasil hoje: reflexões sobre os resultados de uma pesquisa. Cad Saúde Pública 2006; 22:2481-90.

Recebido em 05/Mar/2008

Versão final reapresentada em 19/Ago/2008

Aprovado em 18/Nov/2008 